\title{
Teaching ISOL as a Diplomatic Program: a Case Study in Pusat Budaya Indonesia, Indonesian Embassy of Dili
}

\author{
${ }^{1}$ Danang Satria Nugraha, ${ }^{2}$ R. Kunjana Rahardi, \& ${ }^{3}$ Yuliana Setyaningsih \\ ${ }_{1,2,3}$ Universitas Sanata Dharma, Indonesia \\ 11.s.nugraha@usd.ac.id, ${ }^{2 k u n j a n a @ u s d . a c . i d, ~}{ }^{3}$ yulia@usd.ac.id;
}

\begin{abstract}
Becoming a majority branch program of Badan Pengembangan Bahasa dan Perbukuan, ISOL spread out to many countries around the world. This paper discusses ISOL (Indonesian for Speaker of Other Language) as a kind of diplomatic program. As the pilot project, that program emerged with the policy of education attache in several countries, for example Timor-leste. The data were some evidences from the presentation of ISOL program in KBRI Dili. The results show the description that including (a) description of the ISOL homeinstitution as a administrator, (b) learning material set as a content of program, (c) description of the students, (d) learning supporting factors, and (e) learning barrier factors. In conclusion, the ISOL program in Timor-leste occured in line with the thought declared by Hill (2014) that language as "soft power" in bilateral relations.
\end{abstract}

Keywords: ISOL, Diplomatic Program, Indonesian Embassy of Dili.

\section{PENDAHULUAN}

Sejak dibentuknya wacana internasionalisasi penggunaan bahasa Indonesia (bI) oleh sejumlah akademisi yang kemudian disambut baik oleh pemerintah, Badan Bahasa dan Perbukuan melelaui Pusat Pengembangan dan Strategi Diplomasi Kebahasaan (PPSDK) mengambil kebijakan untuk mengadakan program Pembelajaran Bahasa Indonesia Bagi Penutur Asing (BIPA) di kawasan Asia Tenggara. Pada 2016, PPSDK berhasil mengirimkan lebih kurang 80 tenaga pengajar untuk membuka program tersebut. Salah satu negara terpilih sebagai lokasi pelaksanaan program adalah Timor-leste. Pemilihan tersebut tidak terlepas dari perencanaan bahasa yang dirancang secara baik di Timor-leste. Hajek (2000) menyebutkan adanya tiga periode utama perencanaan bahasa di Timor-leste yang disusun berdasarkan konteks politik, yaitu (a) era bahasa Portugis (1500-an - 1975), (b) era bahasa Indonesia (1975 - 1999), dan (c) era Pasca Referendum Timor-leste (30 Agustus 1999 - sekarang) [1]. TaylorLeech (2009) menyatakan untuk Timor-leste masih berjuang dengan dampak keterbelakangan dan konflik yang parah pada infrastruktur komunikasinya [2, p. 5]. Sementara itu, bagi da Costa Cabral (2018), pemerintah Indonesia memiliki peran yang terpenting dalam pengembangan budaya, politik, dan perencanaan bahasa di Timor-leste [3]. Sebagai sebuah negara baru, Timor-leste menghadapi tantangan pemilihan bahasa sebagai identitas nasional. 
Dalam konteks politik bahasa tersebut, salah satu institusi di Timor-leste yang menyepakati kerjasama untuk melakukan pembelajaran BIPA adalah Pusat Budaya Indonesia, Kedutaan Besar Republik Indonesia untuk Timor-leste. Lembaga tersebut berada di kota Dili, Timor-leste. Pelaksanaan program BIPA di lembaga tersebut sudah dimulai sejak pertengahan Maret 2016. Program tersebut dapat diklasifikasikan ke dalam jenis program perintisan dengan berfokus untuk memperkuat keterampilan berbahasa Indonesia ranah akademik. Albury (2018) menilai program semacam itu sebagai kebijakan bahasa yang diketahui, dilakukan, diinginkan, dan dapat direalisasikan oleh masyarakat sebagai sebuah praktik budaya berpolitik tentang kebijakan berbahasa [4]. Spolsky (2017) berpendapat, "The large number of 2016 papers that Google Scholar finds when you search for "Timor Leste linguas" is a sign that this small newly independent nation is struggling to develop a language policy" [16, p. 11]. Oleh sebab itu, kajian-kajian empiris perlu dilakukan untuk memetakan proses pelaksanaan program.

\section{METODE PENELITIAN}

Penelitian kualitatif ini dilaksanakan secara bertahap dengan mengacu pada metode etnografi yang disusun oleh Blommaert (2009) [7]. Tahapan pertama adalah pengumpulan data. Data dikumpulkan dengan mengunakan metode observasi. Observasi dilaksanakan pada September-Desember 2016 di Pusat Budaya Indonesia, Kedutaan Besar Republik Indonesia untuk Timor-leste. Dalam observasi tersebut peneliti terlibat langsung dalam pelaksanaan program yang menjadi objek penelitian. Instrumen yang digunakan adalah panduan observasi yang dilengkapi dengan catatan lapangan dan alat-alat perekam audio visual. Tahapan pertama diakhiri dengan langkah reduksi data penelitian. Reduksi dilakukan untuk menyeleksi datadata yang tidak memiliki relevansi dengan objek penelitian. Tahapan kedua adalah analisis data yang terdiri atas (a) kodifikasi, (b) klasifikasi, dan (c) triangulasi. Selama kodifikasi, pemberian label data dilakukan berdasarkan jenisnya, yaitu data tertulis dan data lisan, seperti dicontohkan pada data (1), (2), dan (3). Kedua jenis data tersebut, selanjutnya, diklasifikasikan sesuai dengan fokus penelitian ini. Klasifikasi disusun dengan mengacu pada empat aspek pengajaran BIPA sebagai program diplomasi. Pada fase triangulasi, peneliti memeriksa ulang kesahihan data dengan teknik penelaahan berulang. Tahapan ketiga adalah penyajian hasil analisis. Hasil analisis disajikan dengan memanfaatkan uraian-uraian deskriptif. Uraian deskriptif dilengkapi dengan justifikasi dari pakar-pakar teori perencanaan bahasa.

\section{HASIL DAN PEMBAHASAN}

Program pembelajaran BIPA di Timor Leste merupakan langkah strategis yang sedang dilaksanakan oleh pemerintah Indonesia. Dengan mengambil contoh di Australia, sebagaiamana yang dinyatakan Hill (2014) bahwa "in some states the Indonesian government alson assists with the provision of various teacher exchange programmes in schools and Indonesian-language teacher assistans“ [5, p. 9], pembukaan program BIPA pada berbagai lembaga di Timor-leste dapat memberikan pengaruh pada usaha mewujudkan cita-cita menjadikan Bahasa Indonesia sebagai bahasa di kawasan Asia Tenggara. Sekurangkurangnya, masyarakat di kawasan Asia Tenggara mengetahui bahwa Bahasa Indonesia tengah didiplomasikan sebagai suatu alat komunikasi baru untuk memenuhi kebutuhankebutuhan regional. Curtis, Robertson, dan Mahony (2018) menegaskan "it (Indonesian language program) sought to address the broader goal of supporting Asia literacy" [6, p. 2]. Dengan mempertimbangkan situasi dan kondisi yang diuraikan tersebut, kajian ini menyajikan 
deskripsi pelaksanaan pengajaran BIPA di Timor-leste sebagai sebuah bentuk program diplomasi.

\subsection{Lembaga Penyelenggara sebagai Pengontrol Program}

Lembaga yang menjadi lokasi pengajaran BIPA adalah Pusat Budaya Indonesia (PBI). Lembaga tersebut, secara administratif, merupakan lembaga yang berada di bawah KBRI Dili, Timor Leste. Secara khusus, informasi tentang identitas lembaga tersebut dapat disimak pada laman resmi KBRI Dili di www.kemlu.go.id/dili/id/. Nama lembaga dalam bahasa Inggris dan bahasa Indonesia disajikan pada laman tersebut. Termasuk pula di dalamnya dimuat informasi tentang struktur organisasi lembaga dan sistem keorganisasian yang digunakan oleh lembaga tersebut. Berkaitan dengan kehadiran lembaga tersebut, dalam pandangan Baldauf Jr., dkk (2011) dinyatakan bahwa sekurang-kurangnya terdapat tiga parameter penyelenggaraan program, yaitu "(a) the time dedicated to language learning is inadequate, (b) educational materials may not be sufficient or appropriate, dan (c) continuity of commitment may be problematic" [8, p. 312]. Mengacu pada konsep tersebut, PBI memiliki ketiga parameter yang dimaksud.

Program pengajaran BIPA di Pusat Budaya Indonesia, KBRI Dili, dikoordinatori oleh Robert Hedy Soerijayudha, atase pendidikan, dan secara praktis diatur pelaksanaannya oleh Vandha P., direktur Pusat Budaya Indonesia. Pelaksanaan program juga dibantu oleh beberapa staf Pusat Budaya Indonesia yang mendapatkan tugas dalam melaksanakan program BIPA. Secara berkala, baik staf Pusat Budaya Indonesia maupun KBRI Dili memberikan bantuan kepada pengajar PPSDK dalam berbagai kegiatan yang dilaksanakan bersama. Berkaitan dengan pengelola dan penanggung jawab pelaksanaan program BIPA tersebut, Hamid, Nguyen, dan Baldauf, Jr. (2013) menyatakan kebutuhan bahasa yang dirasakan untuk pembangunan nasional dan daya saing ekonomi di dunia yang semakin mengglobal tampaknya menjadi pendorong yang paling kuat di sejumlah negara [9]. Sementara itu, dalam pandangan McDermott (2018), dinyatakan bahwa "power and ideology are central in defining and legitimising what constitutes a language" $[10$, p. 3]. Demikian sinergi antara PBI KBRI Dili dan Badan Pengembangan Bahasa dan Perbukuan dalam upaya melaksanakan pengajaran BIPA bagi penutur bI di Timor-leste.

Perwakilan Indonesia di negara Timor Leste yang menjadi sumber pemberi bantuan kepada pengajar PPSDK adalah Kedutaan Besar Republik Indonesia untuk Timor Leste, Dili. Secara khusus, atase pendidikan dan kebudayaan memberikan perhatian dan dukungan kepada pengajar PPSDK melalui komunikasi yang intensif dan pemberian akses fasilitas pengajaran yang memadai. Sebagai program lanjutan, pelaksanaan pengajaran BIPA di Pusat Budaya Indonesia menjadi bahan perhatian dari pihak kedutaan sebagai wujud dari diplomasi pengenalan budaya Indonesia. Dalam pandangan Heugh dan Stroud (2018), langkah-langkah serupa itu diposisikan sebagai fokus global yang relevan dengan situasi multilingual/ keanekabahasaan [11].

\subsection{Perangkat Pembelajaran sebagai Substansi Program}

Pertama, kurikulum yang digunakan selama mengajar adalah kurikulum BIPA yang dipublikasikan oleh Pusat Pengembangan Strategi dan Diplomasi Kebahasaan (PPSDK). Sesuai dengan tugas mengajar yang diterimakan kepada para pengajar, kurikulum yang digunakan adalah standar kurikulum PPSDK untuk tingkat A1 dan A2. Berkaitan dengan perihal tersebut, dalam pandangan Jourdan dan Salaün (2013), dinyatakan bahwa dokumen 
resmi semacam itu biasanya mengidentifikasi lima latar belakang utama (pedagogis, kultural, politis, etis, dan ekonomis) tentang aspek kebudayaan dan realitas kebahasaan yang perlu diciptakan [12]. Sementara itu, Taylor-Leech (2011) menemukan:

"Since Timor-Leste celebrated its independence in 2002, its education system has undergone substantial change and development. Among the many logistical and educational challenges facing education planners, perhaps the most acute and controversial concern the teaching of languages in the curriculum and the selection of the medium of instruction." [13, p. 289]

Bahwa bahasa instruksional dalam penyelenggaraan pendidikan merupakan aspek yang perlu diperjelas identitasnya merupakan fokus dari penyelenggaraan pendidikan bahasa di Timorleste. Kedua, daftar sumber bahan ajar. Tiga buku yang digunakan adalah (a) Tim Penyusun. 2016. Sahabatku Indonesia Tingkat A1. Jakarta: Pusat Pengembangan dan Pembinaan bahasa., (b) Tim Penyusun. 2016. Sahabatku Indonesia Tingkat A2. Jakarta: Pusat Pengembangan dan Pembinaan bahasa, dan (c) Maesaroh, R. dan Fauzy, E.R. 2016. Materi Ajar BIPA Tingkat Dasar 1. Bandung: Balai Bahasa Universitas Pendidikan Indonesia. Ketiga, media-media yang digunakan.

\subsection{Data dan Gambaran Pemelajar sebagai Sasaran Program}

Pemelajar BIPA di Pusat Budaya Indonesia dapat digambarkan secara deskriptif melalui pemaparan tentang (1) karakter sikap pemelajar dan (2) kemampuan berbahasa pemelajar. Pertama, secara umum, dapat disampaikan bahwa pemelajar BIPA pada periode 25 Juli sampai 30 September 2016 memiliki dua kecenderungan karakter sikap, yaitu (a) karakter acuh (perhatian, ingin tahu, dan ingin mengerti) dan (b) karakter tak acuh (tidak perhatian, tidak ingin tahu, dan tidak ingin mengerti). Dalam pandangan Mirvahedi (2018) dinyatakan bahwa kebijakan bahasa adalah salah satu dari banyak kekuatan struktural yang melibatkan individu secara diskursif secara lintas level dan skala [14]. Kedua, secara umum dapat dinyatakan bahwa kemampuan berbahasa pemelajar BIPA di Pusat Budaya Indonesia sudah berada pada level A1 lanjut dan A2 lanjut. Berdasarkan pengamatan pada proses belajar dan pengukuran melalui tes, dapat diketahui bahwa rata-rata kemampuan berbahasa pemelajar adalah pada level tersebut. Temuan tersebut dipengaruhi oleh fakta bahwa Bahasa Indonesia juga digunakan sebagai bahasa komunikasi sehari-hari oleh masyarakat di Dili dalam porsi penggunaan yang amat terbatas. Oleh sebab itu, kelas-kelas yang saya tangani berorientasi pada pembenahan kemampuan gramatikal dan pengayaan kosakata. Dengan menggunakan latihan-latihan dalam porsi yang banyak, kemampuan dan keterampilan berbahasa Indonesia para mahasiswa dapat ditingkatkan. Hamid, Hoang, dan Kirkpatrick (2018) menilai kegiatankegiatan evaluasi atau latihan terstruktur membawa implikasi pada peningkatkan keterampilan berbahasa [15].

Ketiga, berdasarkan pada data-data pembelajaran di kelas yang terangkum dan tersajikan dalam bagian-bagian sebelumnya, dapat dinyatakan tiga hal sebagai berikut. Pertama, aspek materi pembelajaran. Bagi pemelajar-pemelajar Pusat Budaya Indonesia di Timor Leste yang terklasifikasikan dalam level AI, fokus materi pembelajaran yang paling sesuai adalah peningkatan kompetensi gramatikal dan pengayaan kosakata. Fokus tersebut merupakan pembelajaran lanjutan yang menjadi bekal bagi pemelajar untuk lebih kompeten dan mahir berbahasa Indonesia. Kedua, aspek media pembelajaran. Tidak dapat disangkal, media berupa sajian audio-visual yang disajikan dalam salindia sederhana dapat menarik atensi atau 
perhatian pemelajar. Ketiga, aspek pengajar. Salah satu kunci pengajar dalam mengendalikan dan mengatur kelas menjadi menarik adalah dengan memanfaatkan beberapa kata kunci dalam Bahasa Tetun. Sejauh ini, penghargaan kepada para pemelajar dengan menggunakan kata-kata itu dapat dikatakan cukup efektif. Dengan demikian, pengajar dan pemelajar dapat merasa nyaman dalam kegiatan pembelajaran.

Keenam, berdasarkan pada data-data pembelajaran di kelas yang terangkum dan tersajikan dalam bagian-bagian sebelumnya, dapat dinyatakan tiga hal sebagai berikut. Pertama, aspek materi pembelajaran. Materi (a) ungkapan salam dan cara penggunaannya dan (b) perkenalan diri dapat diajarkan dengan baik melalui model tutorial dengan aktivitas di kelas berdialog/bermain peran. Aktivitas tersebut menjadi lebih efektif dengan pelengkap penjelasan dari pengajar secara kontrastif. Demikian juga dengan materi-materi lainnya. Kedua, aspek media pembelajaran. Media yang sesuai untuk menyampaikan dua materi tersebut adalah berdialog/bermain peran yang disertai dengan latihan menghafal. Ketiga, aspek pengajar. Pengajar dapat selalu mengantisipasi adanya ketidakpahaman pemelajar karena perbedaan stuktur dalam bahasa. Untuk mengantisipasinya, pengajar dapat mempersiapkan diri dengan mencari informasi-informasi untuk disampaikan di dalam kelas.

\title{
3.4 Faktor Pendukung dan Penghambat Program
}

Pendukung dan perkembangan pengajaran BIPA sebagai program diplomasi dipengaruhi oleh beberapa faktor pendukung dan penghambat. Berkaitan dengan faktor tersebut, TaylorLeech (2013) menyatakan fakta bahwa

\begin{abstract}
"After the invasion and annexation of Timor-Leste by Indonesia, Indonesian was imposed as the official language and its use in the education system was compulsory. Modern Indonesian spread rapidly, especially after the public use of Portuguese was forbidden in the 1980s in an effort to exert greater social control." [2, p. 3].
\end{abstract}

Secara khusus, berikut diulas dua faktor pendukung. Pertama, faktor pendukung internal meliputi substansi program, yakni perangkat pembelajaran. Kedua, faktor pendukung eksternal meliputi dua fokus utama. Dalam pandangan Matikainen (2018) dinyatakan bahwa peran guru bahasa akan berkembang di masa depan ketika dapat berubah melampaui model pembelajaran penutur asli dalam pendidikan bahasa [17].

Sementara itu, tantangan dan hambatan perkembangan pengajaran bahasa Indonesia. Informasi kedelapan adalah tantangan dan hambatan perkembangan pengajaran bahasa Indonesia yang dapat diklasifikasikan ke dalam tantangan dan hambatan di dalam kelas dan di luar kelas. Pertama, tantangan dan hambatan di dalam kelas. Secara umum, tantangan dan hambatan di dalam kelas adalah kendala bahasa. Pelajar dengan kemampuan berbahasa Inggris yang terbatas pada beberapa materi susah memahami konsep dan sukar berlatih dalam mengerjakan tugas. Kedua, tantangan dan hambatan di luar kelas meliputi serba-serbi pemahaman lintas budaya (cross culture understanding). Pengajar PPSDK berusaha menempatkan diri dengan tepat di dalam lingkungan kerja dan lingkungan tempat tinggal. Langkah-langkah semacam itu dapat mendukung pelaksanaan pengajaran program BIPA. Dalam pandangan William-van Klinken (2004) ditegaskan bahwa sejak Timor-leste memilih kemerdekaan dari Indonesia pada tahun 1999, Timor-leste telah mengalami perubahan besar dalam bahasa yang digunakan dalam kehidupan publik, dengan bahasa Tetun dan Portugis menggantikan bahasa Indonesia sebagai bahasa resmi [18][19]. 


\section{SIMPULAN}

Berikut disampaikan dua simpulan berdasarkan studi kasus yang dilaksanakan. Pertama, secara khusus, pihak PPSDK hendaknya dapat melakukan jalinan kerjasama dengan Pusat Budaya Indonesia yang menjadi tempat pelaksanaan pengajaran Bahasa Indonesia. Kerjasama diperlukan untuk melanjutkan program yang sudah berjalan. Lebih lanjut, secara kelembagaan, relasi dan jaringan diplomasi dapat semakin ditingkatkan. Peningkatan relasi tersebut menjadi dasar untuk melakukan kegiatan lanjutan yang lebih terstruktur dan terencana. Dengan demikian, pihak PPSDK, Badan Bahasa, dapat menginisiasi program penyebaran Bahasa Indonesia dalam skala yang lebih luas. Kedua, Pusat Budaya Indonesia dapat melakukan koordinasi dan komunikasi dengan seluruh pengajar dan karyawan secara intensif menyangkut pelaksanaan program pengajaran Bahasa Indonesia. Koordinasi dan komunikasi merupakan cara terbaik untuk mempersiapkan program. Persiapan program yang matang dapat memberikan keuntungan pada kedua belah pihak, baik Pusat Budaya Indonesia, Timor Leste, maupun pihak Badan Bahasa, Indonesia. Keuntungan yang direncanakan dapat membawa manfaat yang direncanakan oleh kedua pihak tersebut.

\section{REFERENCES}

[1] J. Hajek, "Language Planning and the Sociolinguistic Environment in East Timor: Colonial Practice and Changing Language Ecologies," Curr. Issues Lang. Plan., vol. 1, no. 3, pp. 400-414, Dec. 2000.

[2] K. Taylor-Leech, "Finding space for non-dominant languages in education: language policy and medium of instruction in Timor-Leste 2000-2012," Curr. Issues Lang. Plan., vol. 14, no. 1, pp. 109-126, Feb. 2013.

[3] I. da Costa Cabral, “" As línguas têm de estar no seu devido lugar' ('languages have to be in their proper place'): language ideologies, languagised worlds of schooling and multilingual classroom practices in Timor-Leste," Curr. Issues Lang. Plan., vol. 20, no. 1, pp. 33-49, Jan. 2019.

[4] N. J. Albury, "Between public perception and government intent in national language policy," Curr. Issues Lang. Plan., vol. 20, no. 2, pp. 160-178, Mar. 2019.

[5] D. T. Hill, "Language as 'soft power' in bilateral relations: the case of Indonesian language in Australia," Asia Pac. J. Educ., vol. 36, no. 3, pp. 364-378, Jul. 2016.

[6] R. Curtis, A. Robertson, and I. Mahony, "Intercultural language learning: the Indonesian for Teachers Initiative (InTI) experience," Lang. Intercult. Commun., vol. 19, no. 4, pp. 357-370, Jul. 2019.

[7] J. Blommaert, Ethnography, Superdiversity, and Linguistic Landscapes: Chronicles of Complexity. Bristol: Multilingual Matters. 2009.

[8] R. B. Baldauf, R. B. Kaplan, N. Kamwangamalu, and P. Bryant, "Success or failure of primary second/foreign language programmes in Asia: what do the data tell us?," Curr. Issues Lang. Plan., vol. 12, no. 2, pp. 309-323, May 2011.

[9] M. O. Hamid, H. T. M. Nguyen, and R. B. Baldauf, "Medium of instruction in Asia: context, processes and outcomes," Curr. Issues Lang. Plan., vol. 14, no. 1, pp. 1-15, Feb. 2013.

[10] P. McDermott, "From ridicule to legitimacy? 'Contested languages' and devolved language planning," Curr. Issues Lang. Plan., vol. 20, no. 2, pp. 121-139, Mar. 2019. 
[11] K. Heugh and C. Stroud, "Diversities, affinities and diasporas: a southern lens and methodology for understanding multilingualisms," Curr. Issues Lang. Plan., vol. 20, no. 1, pp. 1-15, Jan. 2019.

[12] C. Jourdan and M. Salaün, "Vernacular and culturally based education in Oceania today: articulating global, national and local agendas," Curr. Issues Lang. Plan., vol. 14, no. 2, pp. 205-216, May 2013.

[13] K. Taylor-Leech, "Timor-Leste: sustaining and maintaining the national languages in education," Curr. Issues Lang. Plan., vol. 12, no. 2, pp. 289-308, May 2011.

[14] S. H. Mirvahedi, "Sociological realism and language policy analysis: A way forward," Curr. Issues Lang. Plan., vol. 20, no. 3, pp. 309-330, May 2019.

[15] M. O. Hamid, N. T. H. Hoang, and A. Kirkpatrick, "Language tests, linguistic gatekeeping and global mobility," Curr. Issues Lang. Plan., vol. 20, no. 3, pp. 226244, May 2019.

[16] B. Spolsky, "Language policy in Portuguese colonies and successor states," Curr. Issues Lang. Plan., vol. 19, no. 1, pp. 62-97, Jan. 2018.

[17] T. Matikainen, "Towards post-native speakerism: dynamics and shifts," Curr. Issues Lang. Plan., vol. 20, no. 2, pp. 203-206, Mar. 2019.

[18] C. Williams-van Klinken, "Developing Electoral Terminology for a New Official Language: Tetun in East Timor," Curr. Issues Lang. Plan., vol. 5, no. 2, pp. 142 150, May 2004.

[19] K. Saddhono, "Integrating culture in Indonesian language learning for foreign speakers at Indonesian universities," J. Lang. Lit., vol. 6, no. 2, 2015. 